Int. J. Dev. Biol. 50: 619-625 (2006)

doi: $10.1387 / \mathrm{ijdb} .062172 \mathrm{am}$

Original Article

\title{
Cloning and pattern of expression of the shiro-uo vasa gene during embryogenesis and its roles in PGC development
}

\author{
AKIMITSU MIYAKE ${ }^{1,2}$, TAIJU SAITO ${ }^{1,3}$, TOHRU KASHIWAGI ${ }^{1}$, DAISUKE ANDO ${ }^{1}$, AKITSUGU YAMAMOTO ${ }^{4}$, \\ TOHRU SUZUKI ${ }^{5}$, NORIO NAKATSUJI ${ }^{6}$ and TAKAKO NAKATSUJI*,1

\begin{abstract}
${ }^{1}$ Department of Marine Biology, Graduate School of Marine Science and Technology, Tokai University, ${ }^{2}$ Department of Biological Science, Graduate School of Science, Tokyo University ${ }^{3}$ Laboratory of Breeding Science, Graduate School of Fisheries Science, Hokkaido University ${ }^{4}$ Cell Biology, Nagahama Institute of Bio-science and Technology ${ }^{5}$ Laboratory of Bio-industrial Informatics, Graduate School of Agricultural Science, Tohoku University and ${ }^{6}$ Institute for Frontier Medical Sciences, Kyoto University, Japan
\end{abstract}

\begin{abstract}
The vasa genes are expressed in the germ cell lineage in many organisms, but their expression patterns show large variations. Recent studies suggest that vasa transcripts are involved in germ cell lineage development. In this paper, we isolated the vasa cDNA clone from a teleost, shiro-uo, Leucopsarion petersii and examined its expression pattern during embryogenesis. Then, we examined the functional significance of vasa mRNA during the formation of primordial germ cells (PGCs). The amino acid sequence of shiro-uo VASA is $61.1 \%$ identical to that of zebrafish. In whole-mount in situ hybridization, vasa transcripts appeared at the 4- and 8-cell stages as four spots at both ends of two cleavage planes between the lower tier of blastomeres and the yolk cell mass. At the 16-cell stage, eight spots were observed. After the blastula stage, shiro-uo vasa transcripts showed similar localization as in the zeblafish. Ultrastructural analysis of 4-cell stage embryos revealed the presence of a subcellular organelle that resembled "nuage" in the germ cell lineage observed in the embryos of various organisms. We carried out micromanipulation of 4- or 8-cell stage embryos to remove the vasa mRNA-containig spots and then measured the number of the vasa-expressing PGCs in the genital ridge of the manipulated embryos. The numbers decreased when all of the four spots were removed, indicating that the vasa-containing spots at early cleavage stages have important functions in the development of PGCs.
\end{abstract}

KEY WORDS: Shiro-uo, vasa, primordial germ cell (PGC), mRNA localization, teleost

\section{Introduction}

The germ cell lineage is an important and specialized group of cells that possesses the ability to produce gametes and offspring. The morphology of PGCs in various fish is similar to that in other organisms (Braat et al., 1999). PGCs are morphologically distinct from somatic cells because of their large cell size, large nuclei and the presence of "nuage" in their cytoplasm (Mohowald, 1962; Czolowska, 1969; Wolf et al., 1983).

Molecular markers used for identification of PGCs have become useful research tools. The Drosophila vasa homolog gene has been identified in many other organisms, but its expression patterns during early embryogenesis shows large variations (StartGaiano and Lehmann, 2001). During embryonic development in zebrafish, vasa transcrips are localized to the distal parts of the first two cleavage furrows as condensed granules during cleav- age and are eventually localized into four cells in the blastula. The number of vasamRNA-positive cells remains at four until the late blastula stage. Then, zygotic vasa transcription is initiated in PGCs and these vasamRNA-positive cells migrate to the gonads (Olsen et al., 1997: Yoon et al., 1997: Weidinger et al., 1999; Knaut et al., 2000). In medaka, however, vasa mRNA can be detected uniformly among the blastomeres until late gastrulation. Blastomeres with vasatranscripts move in the embryonic body at the early neurula stage and line up along the anterior-posterior axis on both sides of the embryonic body until the 4-somite stage (Shinomiya et al., 2000). For rainbow trout, vasa mRNA-positive cells are detectable later at the 80 -somite stage (Yoshizaki et al., 2000).

It was also reported that vasa RNA is localized to subcellular

Abbreviations used in this paper: PGC, primordial germ cell.

\footnotetext{
*Address correspondence to: Dr. Takako Nakatsuji. Tokai University School of Marine Science and Technology, Orid 3-20-1, Shimizu-ku, Shizuoka 424-8610, Japan. Fax: +81-543-37-0216. e-mail: takako@scc.u-tokai.ac.jp
} 
A shirouo medaka

zebra

frog

homo

mouse

-E----TTTISSTSV--

FTS-

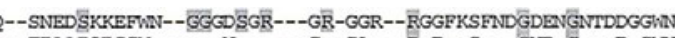

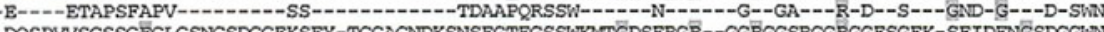
Q

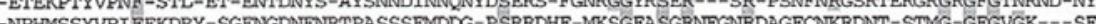

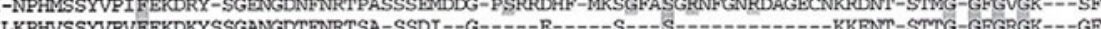

shirouo

medak

zebra

frog

homo

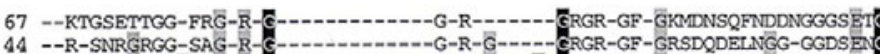
93 GGESRGRGRGGFRGGFRSG-SRDENDENRNDDGWKGG-ESR-ORGRGGFGGSFRGGFRDGGNEDTGRR GFGRENNIENGNDEGGEGRGR-GR-GGP 89 SSERDVFGD-D-ERDQRR GFPGRGGYNGNEDGQKPNAFRGRG GRRNEN-EQRRG-F--GERGGFRSENGORNFDNRGDFGNSGEEEDRRS-YGG-FGGFN

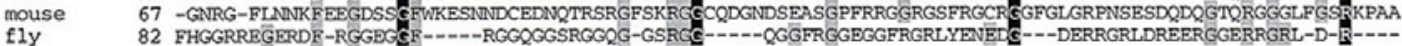

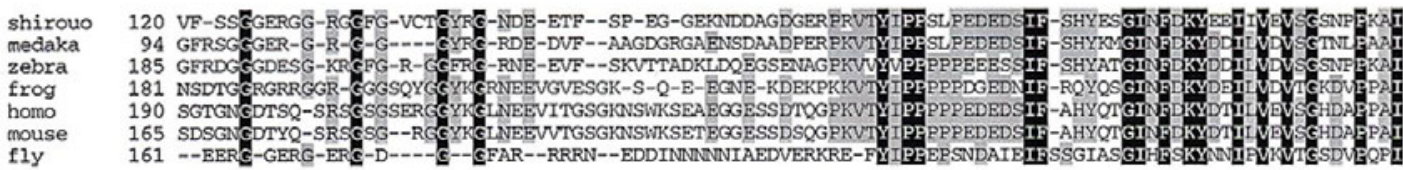

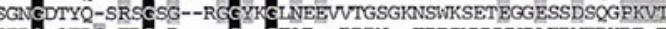

shirouo

medaka

zebra

frog

homo

mouse
fly
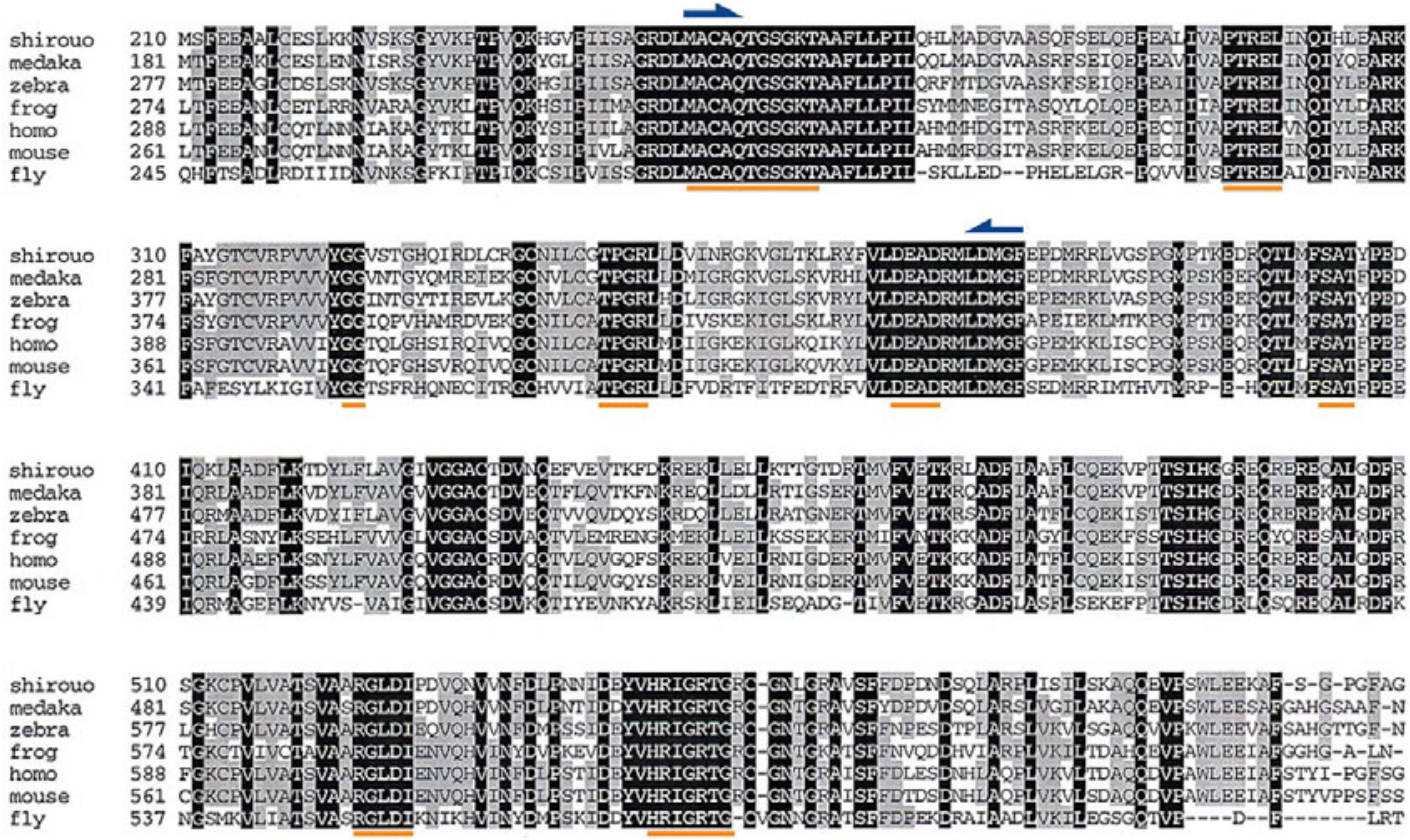

shirouo 606 PAMRGFGATGSRKSAQMTSFQ-NNS-SSQSAA---QSVAEEEDT̄

medaka 579 PSGRTFASTDSRKGG---SFQ-DSSVKTQPAAP--PAAADEDD

zebra 675 PRGKVEASTDSRK-G--GSFKSDEPPPSQTSAPSAAAAAADDEE

$\begin{array}{ll}\text { frog } & 670 \text { S----B-YAA---DSMGEQAGGNAVTTPSF--AQ--E--EEAS } \\ \text { homo } & 686 \text { STR-GNVFASV--DTRK----GKSTLNTAGFSSSOAPNPVDDES }\end{array}$

mouse $\quad 660$ STRGGAVFASV--DTRKNYOGKHTLNTAGISSSOAPNPVDDES

fly 623 CGAGGDGGYSNON--.-.-FGGVDVRGRIYVGDATNVEEBDOND

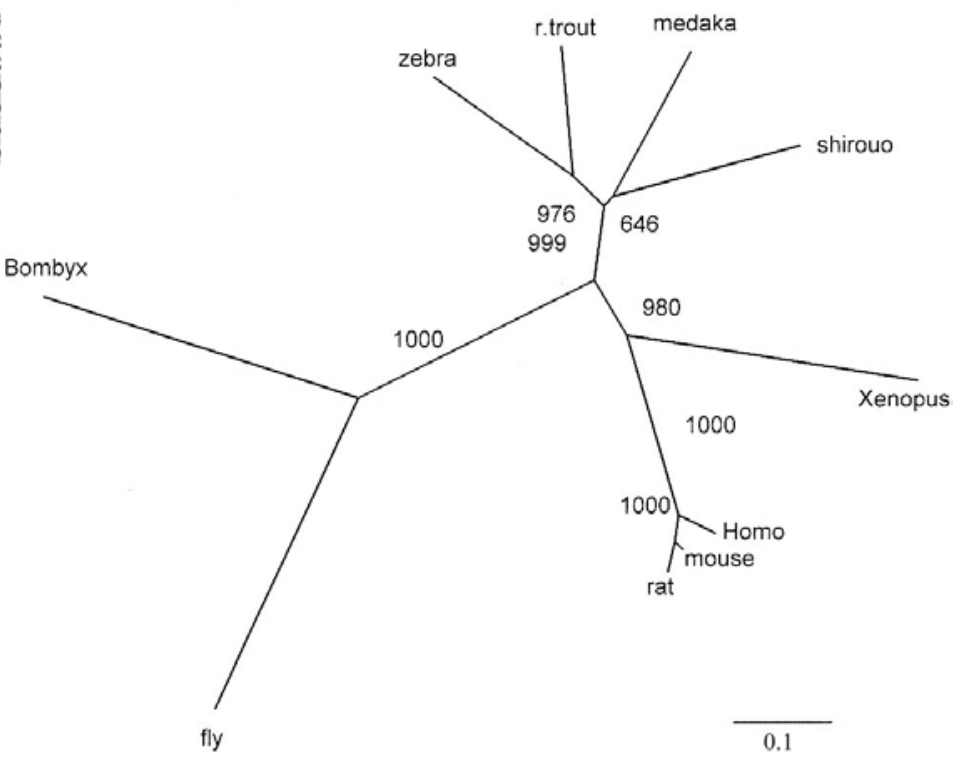

Fig. 1. Sequence and phylogeny of the shiro-uo VASA

protein. (A) The aligment of the shiro-uo VASA protein and the VASA proteins of other animals. The amino acid sequence is $69.7,61.4,52.1,54.3,55.9$ and $45.2 \%$ identical to that of the medaka, zebrafish, Xenopus (frog), Homo sapiens (Homo), mouse and Drosophila (fly) VASA proteins, respectively. Orange lines indicate conserved regions. Arrows indicate the probe region used for whole-mount in situ hybridization. (B) Phylogeny of the VASA proteins. The numbers after the internal branches indicate the bootsrap value (value/1000) for each group. 

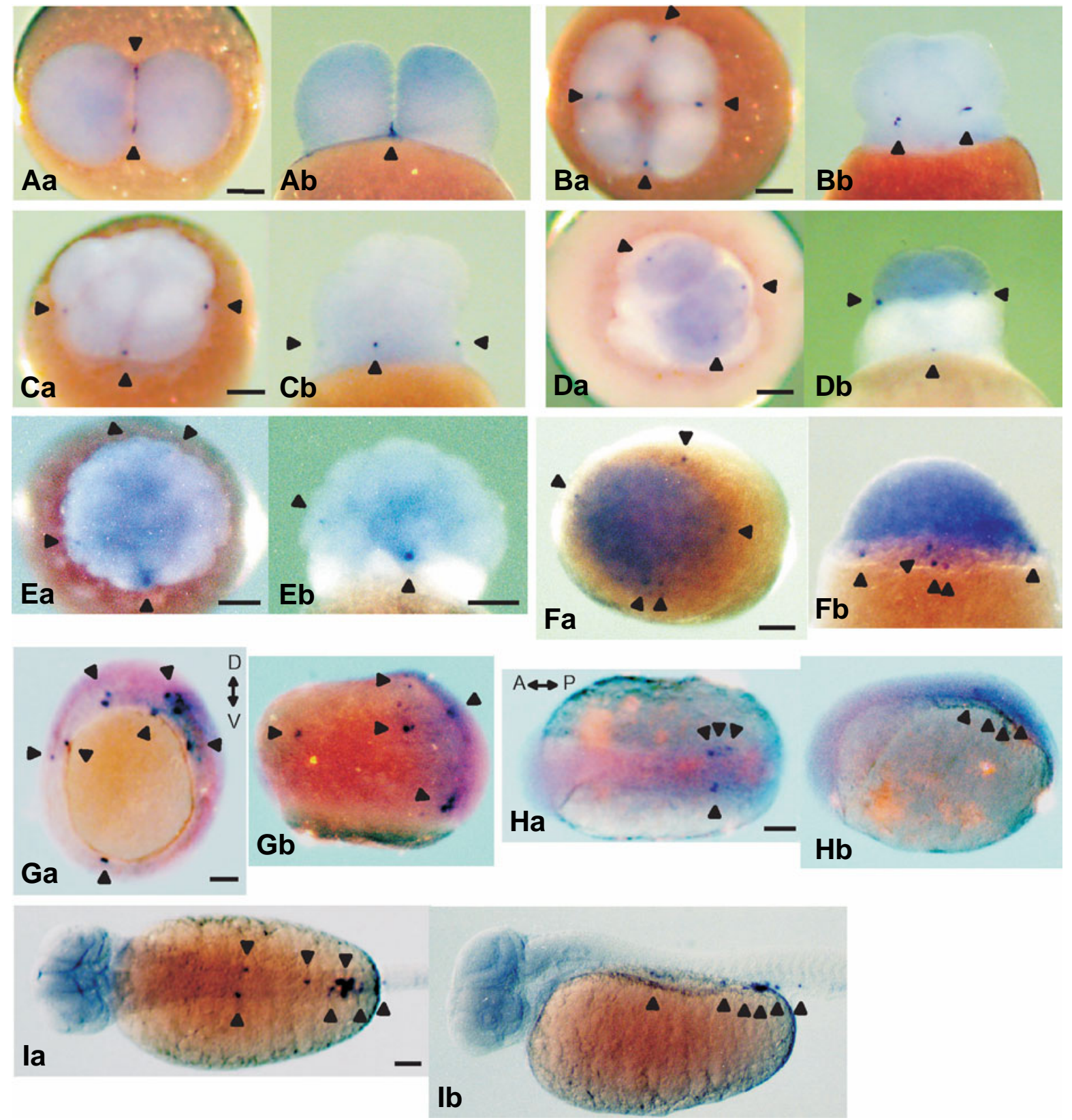

Fig. 2. Whole-mount in situ hybridization using vasa probe. (A) 2-cell stage, (B) 4-cell stage, (C) 8-cell stage, (D) 16-cell stage, (E) 32-cell stage, (F) blastula stage, (G) 90\%-epiboly stage, (H) bud stage and (I) 32-somite stage. (Aa, Ba, Ca, Da, Ea, Fa) view from the animal pole. (Ga) view from

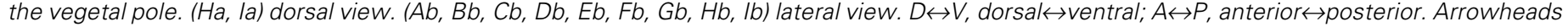
indicate vasa spots $(A, B, C, D, E)$ and vasa positive cells $(F, G, H, I)$. Scale bars, $100 \mu \mathrm{m}$.

structures resembling the germ plasm organelle, "nuage". These expression patterns of vasaRNA are suggestive of its function in PGC development (Knaut et al., 2000). Furthermore, removal of the cytoplasm at the ends of the cleavage planes in zebrafish with the aim of removing vasa and other mRNA components results in a severe reduction in the number of germ cells (Hashimoto et al., 2004).

In this paper, we isolated the vasacDNA from a teleost, shirouo (Family Gobiidae) and studied its expression pattern during embryogenesis while investigating the development of the shiro- uo germ cell lineage. We reported that shiro-uo embryos show a unique cleavage pattern among teleosts (Nakatsuji et al., 1997) and that they are highly transparent and suitable for micromanipulation and other experiments. Furthermore, we examined the functional significance of the vasamRNA-containing spots in the formation of PGCs using micromanipulation. We carried out micromanipulation of 4- or 8-cell stage embryos to remove the vasa mRNA-containig spots and then counted the number of vasa-expressing PGCs in the genital ridges of the manipulated embryos. The numbers decreased significantly when the four 


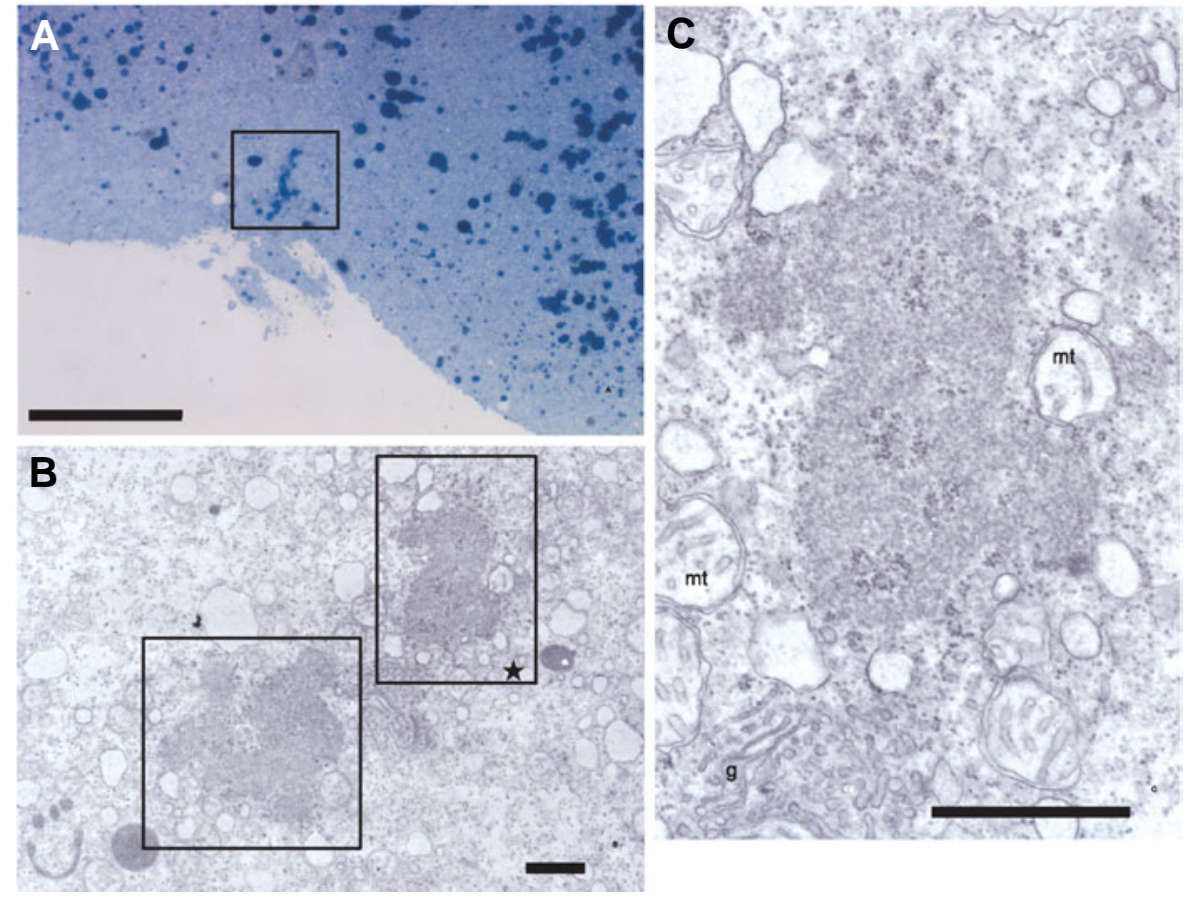

Fig. 3. A semi-thin $(2 \mu \mathrm{m})$ vertical section (A) and electron micrograph (B,C) of the 4-cell stage of the shiro-uo embryo. (A) Distinct aggregated granules, presumable vasa-containing areas, are indicated in the square. (B) A low magnification view of the electron micrograph of the granules indicated in (A). (C) A higher magnification view of the presumptive germ plasm, "nuage", indicated by the square labeled with a star in (B). mt, mitochondria; g, Golgi. Scale bars; $50 \mu m(A) ; 1 \mu m(B, C)$.

spots were removed, indicating that the vasacontaining spots at early cleavage stages have important functions in the development of PGCs.

\section{Results}

\section{Sequence analysis}

We isolated a full-length vasa cDNA clone from shiro-uo, which had an open reading frame of 1938bp and encoded 646 amino acids (Fig. 1A). The amino acid sequence contained eight consensus sequences for the DEAD protein family (Fig.1, underlined). FASTA analysis indicated that the shiro-uo VASA protein is $69.7 \%$ and $61.4 \%$ identical to the medaka (Shinomiya et al., 2000) and zebrafish (Olsen et al., 1997; Yoon et al., 1997), respectively. Additionally, the sequence showed $52.1 \%$ identity to Xenopus (Komiya et al., 1994), 54.3\% identity to Homo sapiens (Castrillon et al., 2000), 55.9\% identity to mouse (Fujiwara et al., 1994) and 45.2\% identity to Drosophila (Hay et al., 1988; Lasko and Ashburner, 1988). A radial phylogenic tree of VASA proteins produced by the Neighbor-joining method indicated that the deduced shiro-uo VASA protein falls into the fish cluster (Fig. 1B).

\section{Expression pattern during embryogenesis}

Whole-mount in situhybridization was carried out using shirouo probes prepared from the 383bp vasacDNA fragment containing the DEAD box region (Fig. $1 A$, arrowed region) and the localization of vasa transcripts was investigated from the 2-cell stage to the 32-somite stage (5 day post-fertilization). At the 2-cell stage, vasa transcripts formed two spots at both ends of the first cleavage plane (Fig. 2A) and at the 4-cell stage, four spots were observed at both ends of the first and second cleavage planes (Fig. 2B). As we have shown previously (Nakatsuji etal., 1997) during shirouo embryogenesis, the third cleavage is horizontal in all blastomeres and produces two tires of blastomeres at the 8-cell stage. The forth cleavage plane is formed vertically in all blastomeres at the 16-cell stage (Arakawa et al., 1999). At the 8-cell stage, vasatranscripts were still observed as four spots at both ends of two cleavage planes between the lower tier of the blastomeres and the yolk cell mass (Fig. 2C). For the 16-cell stage, new vasa spots appeared and we observed eight spots, four of which were still between the lower tier of the blastomeres and the yolk cell mass. The other four spots were present between the upper and lower tiers of the blastomeres (Fig. 2D). At the 32-cell stage, eight vasa transcripts were taken, respectively, into each blastomere located in the lower half of embryos (Fig. 2E). At the blastula stage, the number of vasapositive cells increased and they were clustered (Fig. 2F). By the $50 \%$ epiboly stage, four clusters of vasapositive cells were observed in the marginal region of the blastodisc. At the $90 \%$ epiboly stage, the clusters were observed in the dorsal area of the embryonic body (Fig. $2 \mathrm{G}$ ). By the bud stage, vasa-positive cells were aligned along both sides of the embryonic body in the trunk region (Fig. $2 \mathrm{H}$ ) and for the 12-somite stage, the tailbud detached and vasa-positive cells migrated toward the posterior region along the body axis (data not shown). At the 32-somite stage, vasa-positive cells were observed as aggregates in the presumptive genital ridge region, although some vasa-positive cells were still localized along both sides of the body axis (Fig. 2I).

\section{Ultrastructural analysis}

Semi-thin sections of 4-cell stage embryos were examined by light microscopy. Distinct aggregated granules were observed at the distal ends of the cleavage furrows, presumptive vasa-containing areas (Fig. 3A, square). These granules were distinct from the dark stained round yolk granules. Furthermore, ultrastructural analysis of such granule revealed distinct subcellular structures that resembled nuage, a germ plasm organelle (Fig. 3B, squares). A higher magnification view (square in Fig. 3B) indicated that these nuages were made of fine electron-dense amorphous bodies and were present in close association with mitochondria and the Golgi apparatus (Fig. 3C).

\section{Functional analysis of vasa transcripts}

Because of clear morphological criteria, we can easily identify the region in which vasamRNA may be present. In 4- or 8-stage shiro-uo embryos, the presumed location of the vasa mRNAcontaining four spots can be easily identified. To examine the functional significance of the vasamRNA-containing spots during 
the formation of PGCs, we carried out micromanipulation of 4- or 8-cell stage embryos to remove the cytoplasm at the presumed four sites of the vasamRNA-containing spots and examined the manipulated embryos at later stages. By whole-mount in situ hybridization, the vasa-positive cells in manipulated and staged embryos were counted. When the four spots were removed, the number of PGCs at the bud stage decreased to $11.9 \pm 6.4$ (mean $\pm S D, n=36)$. When those manipulated embryos were examined at the 32-somite stage, the number was 13.1 $\pm 7.3(n=28)$. As a control experiment, we removed the cytoplasm around the animal pole and the number of PGCs in those control embryos were 21.5 $\pm 3.6(n=13)$ at the bud stage and 20.7 $\pm 5.2(n=22)$ at the 32-somite stage. In the untreated embryos, the number of PGCs were $21.6 \pm 4.0(n=11)$ at the bud stage and $21.4 \pm 7.0(n=23)$ at the 32 -somite stage. Thus, the number of vasa-positive cells significantly decreased when all of the four sites, which correspond to the vasamRNA-containing spots, were removed from the cleavage stage embryos (t-test: $p<0.01)$ (Fig.4).

\section{Discussion}

In the present study, we cloned and examined the shiro-uo (ice goby), Leucopsarion petersii, vasa gene and identified the eight conserved homology boxes present in all DEAD box proteins. The shiro-uo VASA protein also shares with other VASA-related proteins an $\mathrm{N}$ terminus rich in glycine, with multiple repeats of an RGG motif (Fig. 1).

The expression patterns of vasa transcripts during cleavage stages show significant variations among fish. In shiro-uo, upon initiation of the first cleavage, vasa transcript-containing spots were not detectable yet in the whole-mount samples, although there were partial aggregates at the center of the blastomere detectable in histlogical sections of whole- mount samples after in situhybridization (data not shown). The four vasaspots became visible at the 4-cell stage. In ukigori and goldfish embryos at the 8-cell stage, vasa transcript accumulation results in eight vasa spots (Otani et al., 2002; Saito et al., 2004). In the shiro-uo 8-cell stage embryos, however, only four vasa spots were observed at both ends of two cleavage planes between the lower tier of the blastomeres and the yolk cell mass, as same as at the 4-cell stage (Fig. 2C). In our previous study on the shiro-uo, involving celllineage examination via the injection of a tracer dye, we found that the PGCs mainly originated from lower blastomeres at the 8-cell stage (Saito et al., 2002) and this could be explained by the localization of vasa transcripts at the 8-cell stage. At the 16-cell stage, four new vasa spots appeared between the upper and lower tires of the blastomeres and thus resulted in eight vasa spots (Fig. 2D). These four new spots may be formed by division of the four original vasa spots, or by newly concentrated vasa mRNA. Similarly, in ukigori and goldfish embryos at the16-cell stage, eight vasaspots are present. In contrast, for zebrafish the vasa spots only total four from the 4-cell stage until the 32-cell stage (Olsen et al., 1997; Yoon et al., 1997). After the blastula stages, the expression patterns of vasa transcripts show more similarity among teleost species.

Detection of "nuage-like" subcellular structures using electron microscopy revealed the presence of amorphous fine granules and mitochondria, indicating similarity between the vasacontaining complex and the germ plasm of various groups of organisms.

Removal of vasa-containing spots resulted in a significant decrease in PGCs. The number of PGCs was, however, not always lower than that of the controls. This could be due to incomplete removal of vasa-containing spots. Also, the vasacontaining complex might not be confined to the spots but also be more diffusely distributed, which might be the origin of the four new spots at the 16-cell stage. In such a case, complete removal
A

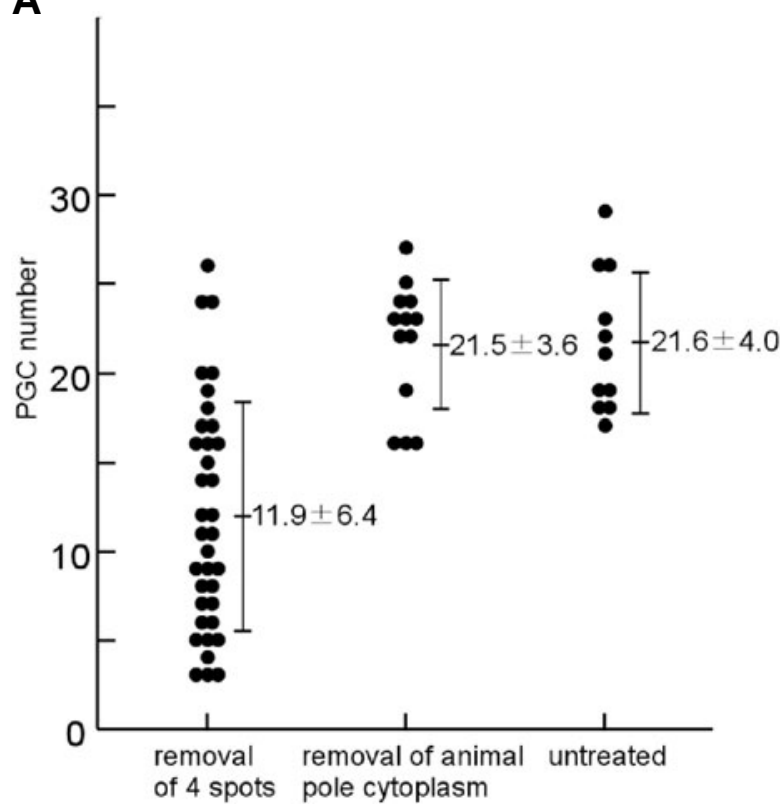

B

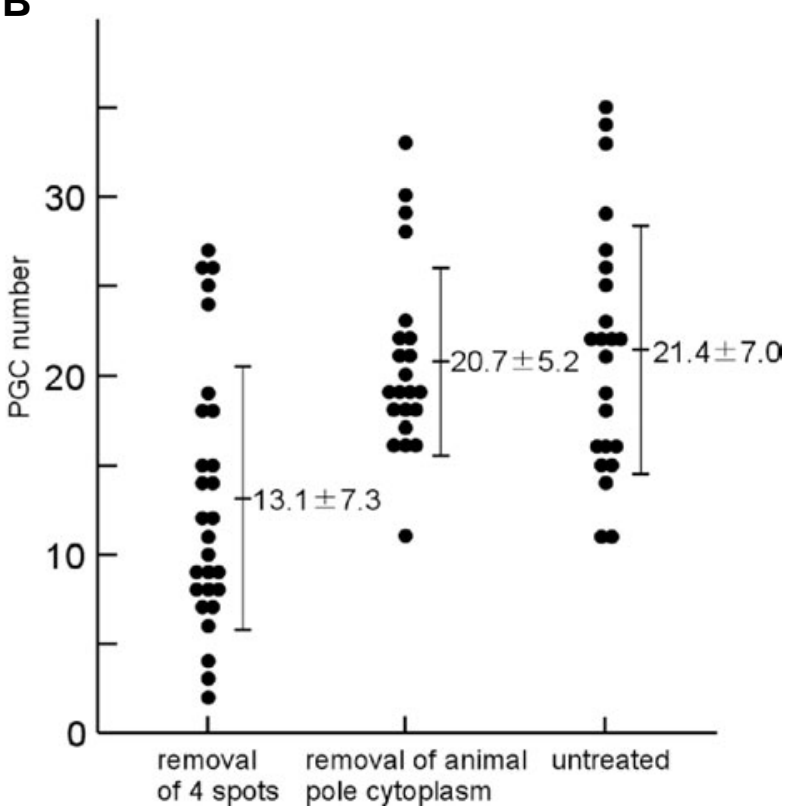

Fig. 4. Removal of the vasa-containg cytoplasm resulted in a decrease in the number of primordial germ cells. (A) The number of $P G C S$ counted at the bud stage. (B) The number of PGCs counted at the 32-somite stage. 
would be difficult and it may be the reason of decreased but remaining number of PGCs. Recent studies have shown that nanos 1, deadend, zDazland bru/mRNAs are also localized to the ends of the cleavage furrows at the 4-cell stage and that their distribution is very similar to that of vasa during early zebrafish development (Köprunner et al., 2001; Weidinger et al., 2003; Hashimoto et al., 2004; Theusch et al., 2006). Our micromanipulation probably removed these complexes at the same time. Taken together, we conclude that the vasacontaining spots at early cleavage stages are functionally important in the development of PGCs in shiro-uo.

\section{Materials and Methods}

\section{Embryos}

Shiro-uo embryos were obtained by artificial insemination as described previously (Arakawa et al., 1999). Fertilized eggs and embryos were cultured at $19^{\circ} \mathrm{C}$ in diluted $(10 \%)$ sterile Hank's salt solution. The chorion was removed manually using forceps in diluted $(50 \%)$ sterile Hank's salt solution supplemented with $5 \mathrm{mM} \mathrm{CaCl} 2$.

\section{cDNA Cloning of Shiro-uo vasa}

mRNAs were extracted from 30 shiro-uo embryos at the 4- to 5-somite using a QuickPrep Micro mRNA Purification Kit (Amersham Pharmacia Biotech). First strand cDNAs were synthesized using an oligo (dT) primer and 2nd strand cDNAs were generated using a TimeSever cDNA Synthesis Kit (Amersham Pharmacia Biotech). The following PCR primers were designed using a highly conserved region of vasa homologous to that found in zebrafish (Olsen et al., 1997; Yoon et al., 1997), Xenopus (Komiya et al., 1994), mouse (Fujiwara et al., 1994), rat (Komiya and Tanigawa, 1995) and Drosophila (Hay et al., 1988; Lasko and Ashburner, 1988 ) to amplify a 383bp cDNA fragment of the vasa gene including the DEAD-box RNA helicase domain;

5'-ATGC(ATGC)TG(CT)GC(ATGC)CA(AG)AC(ATGC)G-3'(upper) and 5'-(AG)AA(ATGC)CCCAT(AG)TC(ATGC)AGCAT-3'(lower). To isolate a full-length coding sequence, 5'- and 3'-RACE were performed after determining the DNA sequence of the $383 \mathrm{bp}$ cDNA fragment of the vasa gene. For 5'-RACE, mRNA was extracted from shiro-uo ovaries and firststrand cDNA was synthesized using a SMART cDNA Library Construction Kit (Clontech). For 3'-RACE, a shiro-uo embryonic cDNA library in the $\lambda$ zapll vector (Stratagene) was used. The primer sequences used for 5'and 3 '-RACE were as follows.

5'-RACE; 5'-CCTAGCCTCAAGGTGAATCTGGTTG-3' and

5'-TGCTACGCCGTCTGCCATAAGATGC-3'.

3'-RACE; 5'-GTAAGCCACAGGACACCAGATCAGAG-3' and

5'-GTATTGGACGAGGCTGACCGAATGC-3'.

The sequence data of the full-length vasa gene are available from DDBJ under accession number (AB098252).

\section{Whole-mount in situ hybridization}

Staged embryos were fixed overnight at $4^{\circ} \mathrm{C}$ with $4 \%$ paraformaldehyde dissolved in 50\% PBS. In situ hybridization was performed as previously described (Jowett and Lettice, 1994) using Digoxigenin (Dig)labeled riboprobes, which were prepared from the $383 \mathrm{bp} \mathrm{cDNA}$ fragment of shiro-uo vasacontaining the DEAD-box region. Antisense RNA probes were generated using T7 RNA polymerase (Roche).

\section{Electron microscopy}

Embryos were fixed with a mixture of $4 \%$ paraformaldehyde and $5 \%$ glutaraldehyde in $0.1 \mathrm{M} \mathrm{PBS}$, rinsed with $0.1 \mathrm{M} \mathrm{PBS}$ and post-fixed with $1 \%$ osmic acid in $0.1 \mathrm{M}$ cacodylate buffer. After dehydration through an ethanol series and propylene-oxide, embryos were embedded in Epon, separated from the yolk mass and cut along the animal-vegetal axis.
Semi-thin $(2 \mu \mathrm{m})$ sections were examined by light microscopy and were then cut to $80 \mathrm{~nm}$ for electron microscopy examination.

\section{Micromanipulation}

Dechorionated embryos were horizontally laid along the side of slide glass in a $60 \mathrm{~mm}$ plastic dish containing diluted $(50 \%)$ culture medium supplemented with $2 \%$ albumen and $5 \mathrm{mM} \mathrm{CaCl}_{2}$. Approximately $50 \mathrm{pl}$ of cytoplasm, at the ends of the cleavage furrows in which vasa transcripts are localized at the 4- or 8-cell stage, was removed from each site with sterile Femtotips II (Eppendorf) and injection equipment (IM-6-2 Microinjector, NARISHIGE). The tip of Femtotipsll was cut to $6 \mu \mathrm{m}$ diameter for use. We removed all the cytoplasm of the four sites at the ends of the cleavage furrows in which vasa transcripts were presumably contained. We removed only a limited amount of cytoplasm, ca. $50 \mathrm{pl}$, from each of the presumed vasa-containing spots for a maximum total of $200 \mathrm{pl}$ from each embryo to avoid interfering with embryonic development and limiting survival. Thirty minutes was allowed to pass to permit the ablated embryos to recover and they were then transferred to dilute (50\%) fresh sterile media supplemented with $5 \mathrm{mM} \mathrm{CaCl}_{2}$, antibiotics (100 units/ $\mathrm{ml}$ penicillin and streptomycin) and methylene blue. The manipulated embryos were maintained in culture until the bud or 32-somite stage and then fixed with $4 \%$ paraformaldehyde. In situ hybridization was then performed as described and the number of vasa-positive cells was counted.

\section{Acknowledgements}

We thank Dr. H. Takeda for his critical reading of the manuscript. We also thank Mr. and Mrs. T. Matsuura, Mr. and Mrs. K. Toritake, Mr. K. Furukawa and Mr. K. Saito for the supplies of shiro-uo adult fish. This work was supported in part by the Research and Study Program of the Tokai University Educational System General Research Organization.

\section{References}

ARAKAWA, T., KANNO,Y., AKIYAMA, N., KITANO, T., NAKATSUJI, N. and NAKATSUJI, T. (1999) Stages of embryonic development of the ice goby (shirouo), Leucopsarion petersii. Zool. Sci. 16: 761-773.

BRAAT, A. K., SPEKSNIJDER, J. E. and ZIVKOVIC, D. (1999) Germ line development in fishes. Int. J. Dev. Biol. 43: 745-760.

CASTRILLON, D. H., QUADE, B. J., WANG, T. Y., QUIGLEY, C. and CRUM, C. P. (2000) The human VASAgene is specifically expressed in the germ cell lineage. Proc. Natl. Acad. Sci. USA 97: 9585-9590.

CZOLOWSKA, R. (1969) Observations on the origin of the "germinal cytoplasm" in Xenopus laevis. J. Embryol. Exp. Morphol. 22: 229-251.

FUJIWARA, Y., KOMIYA, T., KAWABATA, H., SATO, M., FUJIMOTO, H., FURUSAWA, M. and NOCE, T. (1994) Isolation of a DEAD-family protein gene that encodes a murine homolog of Drosophila vasa and its specific expression in germ cell lineage. Proc. Natl. Acad. Sci. USA 91: 12258-12262.

HASHIMOTO, Y., MAEGAWA, S., NAGAI, T., YAMAHA, E., SUZUKI, H., YASUDA, K. and INOUE, K. (2004) Localized maternal factors are required for zebrafish germ cell formation. Dev. Biol. 268: 152-161.

HAY, B., JAN, L. Y. and JAN, Y. N. (1988) A protein component of Drosophilapolar granules is encoded by vasa and has extensive sequence similarity to ATPdependent helicase. Cel/55: 577-587.

JOWETT, T. and LETTICE, L. (1994) Whole mount in situhybridization on zebrafish embryos using a mixture of digoxigenin and fluorescent probes. Trends Genet. 10: 73.

KNAUT, H., PELEGRI, F., BOHMANN, K., SCHWARZ, H. and NÜSSLEINVOLHARD, C. (2000) Zebrafish vasa RNA but not its protein is a component of the germ plasm and segregates asymmetrically before germline specification. J. Cell.Biol.149: 875-888.

KOMIYA, T. and TANIGAWA, Y. (1995) Cloning of a gene of the DEAD box protein family, which is specifically expressed in germ cells in rats. Biochem. Biophys. Res. Commun. 207: 405-410. 
KOMIYA, T., ITOH, K., IKENISHI, K. and FURUSAWA, M. (1994) Isolation and characterization of a novel gene of the DEAD box protein family which is specifically expressed in germ cells of Xenopus laevis. Dev. Biol. 162: 354-363.

KÖPRUNNER, M., THISSE, C., THISSE, B. and RAZ, E. (2001) A zebrafish nanosrelated gene is essential for the development of primordial germ cells. Genes Dev. 15: 2877-2885.

LASKO, P. F. and ASHBURNER, M. (1988) The product of the Drosophila gene vasa is very similar to eakaryotic initiation factor-4A. Nature 335: 611-617.

MAHOWALD, A. P. (1962) Fine structure of pole cell and polar granules in Drosophila melanogaster. J. Exp. Zool. 151: 201-215.

NAKATSUJI, T., KITANO, T., AKIYAMA, N. and NAKATSUJI, N. (1997) Ice goby (shiro-uo), Leucopsarion petersii, may be a useful material for studying teleostean embryogenesis. Zool. Sci. 14: 443-448.

OLSEN, L. C., AASLAND, R. and FJOSE, A. (1997) A vasa-like gene in zebrafish identifies putative primordial germ cells. Mech. Dev. 66: 95-105.

OTANI, S., MAEGAWA, S., INOUE, K., ARAI, K. and YAMAHA, E. (2002) The germ cell lineage identified by vas-mRNA during the embryogenesis in goldfish. Zool. Sci. 19: 519-526.

SAITO, T., OTANI, S., FUJIMOTO, T., SUZUKI, T., NAKATSUJI, T., ARAI, K. and YAMAHA, E. (2004) The germ line lineage in ukigori, Gymnogobius species (Teleostei: Gobiidae) during embryonic development. Int. J. Dev. Biol. 48: 10791085.

SAITO, T., OTANI, S., NAGAI, T., NAKATSUJI, T., ARAI, K. and YAMAHA, E. (2002) Germ cell lineage from a single blastomere at 8-cell stage in shiro-uo (ice goby). Zool. Sci. 19: 1027-1032.

SHINOMIYA, A., TANAKA, M., KOBAYASHI, T., NAGAHAMA, Y. and HAMAGUCHI, S. (2000) The vasa-like gene, olvas, identifies the migration path of primordial germ cells during embryonic body formation stage in the medaka, Oryzias latipes. Develop. Growh Differ. 42: 317-326.
STARZ-GAIANO, M. and LEHMANN, R. (2001) Moving towards the next generation. Mech. Dev. 105: 5-18.

THEUSCH, E. V., BROWN K. J. and PELEGRI, F. (2006) Separate pathways of RNA recruitment lead to the compartmentalization of the zebrafish germ plasm. Dev. Biol. 292: 129-141.

WEIDINGER, G., WOLKE, U., KÖPRUNNER, M., KLINGER, M. and RAZ, E. (1999) Identification of tissues and patterning events required for distinct steps in early migration of zebrafish primordial germ cells. Development 126: 5295-5307.

WEIDINGER, G., STEBLER, J., SLANCHEV, K., DUMSTREI, K., WISE, C., LOVELL-BADGE, R., THISSE, C., THISSE, B. and RAZ, E. (2003) dead end, A novel vertebrate germ plasm component, is required for zebrafish primordial germ cell migration and survival. Curr. Biol. 13: 1429-1434.

WOLF, N., PRIESS, J. and HIRSH, D. (1983) Segregation of germline granules in early embryos of Caenorhabditis elegans: an electron microscopic analysis. J. Embryol. Exp. Morphol. 73: 297-306.

YOON, C., KAWAKAMI, K. and HOPKINS, N. (1997) Zebrafish vasa homologue RNA is localized to the cleavage planes of 2- and 4-cell stage embryos and is expressed in the primordial germ cells. Development 124: 3157-3165.

YOSHIZAKI, G., SAKATANI, S., TOMINAGA, H. and TAKEUCHI, T. (2000) Cloning and characterization of a vasalike gene in rainbow trout and its expression in the germ cell lineage. Mol. Reprod. Develop. 55: 364-371.

Received: April 2006

Reviewed by Referees: April 2006

Modified by Authors and Accepted for Publication: April 2006 Published online: June 2006

Edited by: Makoto Asashima 